\title{
Infant Mortality in Uganda: \\ Determinants, Trends, and the Millennium Development Goals
}

\author{
Sarah Ssewanyana \\ Economic Policy Research Centre \\ and \\ Stephen D. Younger \\ Cornell University
}

January, 2005

We are grateful to David Sahn and Peter Glick for comments. This research is supported by SAGA, a cooperative agreement between USAID and Cornell and Clark-Atlanta Universities. See www.saga.cornell.edu. 


\begin{abstract}
Unusually for an African economy, Uganda's growth has been rapid and sustained for an extended period of time. Further, this growth has clearly translated into substantial declines in poverty for all socio-economic groups and in all regions of the country. Despite this, there is concern in the country that other indicators of well-being are not improving at the same rate as incomes. This paper studies one such indicator, infant mortality. We use three rounds of the Uganda Demographic and Health Surveys to construct a national time series for infant mortality over a long period of time, 1974-1999. We also use these survey data to model the determinants of infant mortality and, based on those results, to examine the likelihood that Uganda will meet the Millennium Development Goal of halving infant mortality by 2015.
\end{abstract}

Key results of the paper include:

- household incomes and infant mortality are significantly negatively correlated, but the correlation is small, so that even if Uganda's rapid growth were to continue for another decade the impact on IMRs will be small up to 2015;

- after controlling for individual, household, and community determinants, there is no discernable time trend (up or down) in infant mortality in Uganda;

- observed improvements in mothers' primary school graduation rates will have a significant impact on IMRs. Plausibly attainable improvements in mothers' secondary graduation rates will have a lesser impact, largely because the improvements in graduation rates are not as great as at the primary level;

- improvements in vaccinations for childhood diseases and in general health care services can also cause significant reductions in IMRs;

- nevertheless, even under optimistic assumptions about improvements in health care and education, Uganda will not achieve the MDG for infant mortality. 


\section{Introduction}

Despite concerns over the most recent poverty numbers, Uganda has experienced rapid economic growth over the past fifteen years, with concomitant reductions in poverty (Appleton, 2001; Appleton and Ssewanyana, 2003). Despite this progress, there is concern in Uganda that living standards are not improving by anything like the quantitative analysis of household expenditures suggests. Both of Uganda's Participatory Poverty Assessments (UPPAP) find that focus group participants and key informants are only slightly more likely to say that poverty has declined rather than increased in their community (UPPAP, 2000, 2002). In addition, there is concern among policy makers and stakeholders other dimensions of well-being, especially health, are not improving over time despite the substantial increases in Ugandans' incomes. In particular, several reports have noted that infant and child mortality rates improved rapidly as the country emerged from the protracted civil conflicts of the 1970s and 1980s, but then leveled off in the mid-1990s, even though economic growth continued (Moller, 2002; Ministry of Finance, Planning and Economic Development (MoFPED), 2003; Uganda Bureau of Statistics, 2001). It is especially disturbing that infant mortality rates in Uganda remain among the highest in Africa and the world.

The Ministry of Finance, Planning, and Economic Development has addressed this paradox (MoFPED, 2003), though most of its strategies for interventions to improve infant mortality rates are drawn from other countries' experiences. Five key areas of intervention were identified as the most effective ways of reducing infant and maternal mortality, including malaria control, improving quality of health care, sanitation, community development, and family planning. This paper addresses similar questions and policies, but it is based on evidence from Uganda itself that will help inform the ongoing debate surrounding infant mortality in that country.

Our approach is unusual in that even though the puzzling data are national averages over time -macroeconomic, one might say -- we estimate mortality probability equations for individual children, a microeconomic approach. Nevertheless, by using the retrospective data from the birth histories in all three of Uganda's Demographic and Health Surveys (UDHS), we are able to expand the microeconomic analysis to include certain time series elements such as trends and national HIV infection rates. This approach is driven by our earlier attempts to estimate strictly time-series regressions of the national infant mortality rate on Gross Domestic Product (GDP) per capita, HIV infection rates, vaccination rates, etc. These attempts failed to produce sensible and statistically significant correlations, largely because the data are relative few, about 25 annual observations. Estimating our model on individual-level data gives us two advantages. First, it allows us to control for a variety of individual, household, and community factors that help to determine mortality rates but that the national-level time series model cannot include. This yields more precise estimates for some of the national-level variables. More importantly, the effects of the individual, household, and community factors are themselves of interest, providing a richer picture of the determinants of infant mortality in Uganda.

In addition to providing a long time series of data, combining all three UDHS surveys offers the advantage of a very large sample, more than 60,000 births. As Mosley and Chen (1984) noted, 
infant mortality is a rare and statistically noisy event, so it is essential that any analysis of its determinants be based on a large sample.

In addition to addressing the paradox between rapid economic growth and stagnant infant mortality rates, our estimates also allow us to project forward infant mortality rates. Such predictions are useful for evaluating the likelihood that Uganda will achieve the Millennium Development Goal for infant mortality, a second main purpose of this paper.

The paper is organized as follows. The next section presents the basic descriptive information on infant mortality that is the source of concern over infant mortality along with a review of existing literature on infant mortality in Uganda. Section 3 presents out estimation approach and a description of the dataset used and the definition of variables. The descriptive statistics of the model variables are also presented in this section. Section 4 presents the estimation results. Section 5 uses these results to project infant mortality rates to 2015, the year that Uganda hopes to achieve the Millennium Development Goal. This section includes several simulations of the impact of improvements in health and education policy on infant mortality. Section 6 concludes with the paper's implications for policy.

\section{Background}

Figure 1 gives the basic data that are the source of the controversy and concern surrounding infant mortality in Uganda. Each line segment represents the infant mortality rate calculated by the Uganda Bureau of Statistics (UBoS) and Macro International for five-year cohorts of children born to women aged 15 to 49 surveyed in the three UDHS surveys. After a sharp peak in the late 1970s and early 1980s - possibly due to the civil conflicts of the time, economic mismanagement, and general decline in the quality of public services - infant mortality appeared to be declining steadily ... until the 2000 UDHS results. That survey had a much higher estimate for infant mortality in the 1991-1995 cohort than the 1995 survey: 91 vs. 81 per thousand births. More importantly, it showed no trend improvement in infant mortality over the past 15 years. Taken together, the three surveys suggest that improvement in IMR has leveled off, even as economic growth has taken off. Thus, Uganda almost surely missed the Poverty Eradication Action Plan's ${ }^{1}$ of 78 infant deaths per thousand births in 2002, and it will probably miss the 2005 target of 68. It is especially discouraging that this has happened during a period in which government health expenditures have increased substantially. From a modest base of 1.6 percent of GDP in 1990, government health expenditures rose steadily during the 1990s to reach 3.4 percent of GDP, which itself has increased considerably, in 2001.

Empirical evidence explaining the persistently high IMR in Uganda remains scanty. At a national level, previous work in Uganda has linked the variations in IMR to the HIV/AIDS epidemic (UNDP, 2002; Ntozi \& Nakanaabi, 1997). However, Okuonzi (2002) argues persuasively that the association between the trends in HIV/AIDS prevalence and infant mortality is contrary to expectations in the late 1990s, precisely the period that has caused the most concern. At a microeconomic level, Moller (2002) and Katende \& Twesigye (2002) examine simple and

\footnotetext{
${ }^{1}$ The Poverty Eradication Action Plan (PEAP) is Uganda's version of a Policy Reduction Strategy Paper.
} 
multivariate correlations of a variety of household and community variables with infant mortality.

Figure 1 - Infant Mortality Rates in Uganda

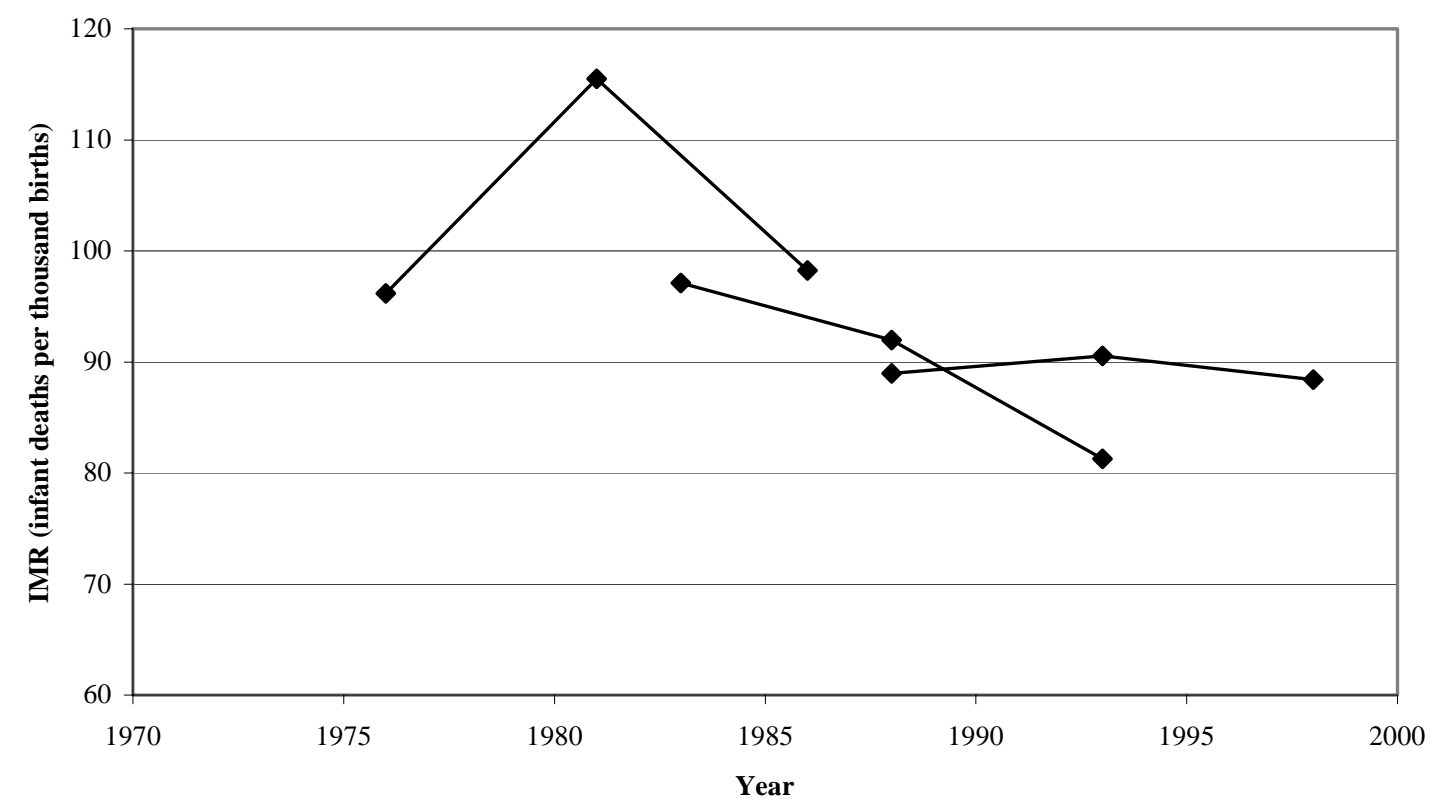

Source: Uganda Bureau of Statistics and ORC Macro, 2001.

\subsection{Defining the Infant Mortality Rate}

To explore these IMR-poverty linkage, this paper uses data from the same UDHS surveys as the $\mathrm{UBoS} /$ Macro report, but the approach here is different in several ways, beginning with the definition of the infant mortality rate. Calculating IMRs for a given time period would seem to be a simple task: take all the children born in a given period, say, a calendar year; wait one year; count the number of deaths; and divide the deaths by the number of children born. This is, in fact, the approach taken in this paper. While straightforward, it has one important limitation: it cannot provide an estimate of the IMR for the period one-year immediately prior to the survey. Children born with a year before the survey will be censored in the sense that they will not have yet lived a year, and thus not run all the risks of death before reaching their first birthday. As such, IMRs based on these children will be biased downward. While this may not seem too important a limitation for IMRs, it is quite important for child or under-five mortality rates. For these, this simple method could not provide information for the five years prior to the survey.

To work around this limitation, the UBoS/Macro study uses a quite complex method based on synthetic cohorts of infants at risk to calculate infant mortality rates for a given time period. Descriptions of the method can be found in Rutstein (1983) and Somoza (1980). The justification for this complexity is that it allows the researcher to calculate mortality rates for dates close to 
the survey date. However, because this study investigates only infant mortality, it uses "natural" cohorts and the calculation described above, thus sacrificing one year of data from each survey for the sake of simplicity. That said, the IMRs used here and the IMRs from the UBoS/Macro study are not significantly different (Figure 2$)^{2}$

One interest of this paper is to examine the time series of infant mortality in detail. This is possible because the UDHS asks women about their entire birth histories. So, for example, a 40year-old woman interviewed in 1988 may have had a child 20 years prior, in 1968, and the survey asks about this child's survival. By using these birth histories, it is possible to construct IMRs for many years prior to the survey date. This, too, requires a modification of the paper's methods in comparison with UBoS/Macro. The fact that infant mortality is negatively correlated with mother's age introduces a possible bias to the IMR calculations for periods far prior to the survey date. Suppose that we want to construct birth histories over the past 15 years. The survey interviews women between the ages of 15 and 49 today, so the information it has on births and deaths 15 years ago is for women who were zero to 34 years old at that time, and the estimated IMR for the earlier period would be biased upward because the sample of mothers is younger. At the same time, there are some mothers who are less than 15 today, but we do not have information on them because the survey collects only information on women older than 15 . So an estimate of current infant mortality will be biased downward. To avoid these biases, this paper uses only children whose mothers were 15 to 34 years old at the time of birth. ${ }^{3}$

A third difference between the IMRs used here and those of UBoS/Macro is that this paper uses one-year rather than five-year cohorts. In sum, the IMRs used here are for one-year cohorts of children born up to fifteen years prior to each survey date to mothers age 15 to 34, calculated as the number of children from that cohort who died before age one divided by the total number of children in the cohort. Before proceeding, it is useful to compare annual estimates of IMRs using synthetic cohorts as in UBoS/Macro and using birth cohorts as in the remainder of this paper. Figure 2 shows such a comparison for the 1988 and 2000 UDHS surveys. ${ }^{4}$ While there are some years with quite different estimates -- mostly due to the fact that the results for synthetic cohorts are smoother because the average data from surrounding cohorts -- none of the differences is statistically significant at the ten percent confidence level. Further, the overall trends for the two series are quite similar, including the apparently flattening of the trend in recent years that concerns policymakers, and there does not appear to be any pattern to the difference in the two series.

\footnotetext{
${ }^{2}$ Note that both the methods are so-called direct estimates of infant mortality.

${ }^{3}$ Using such long lags leads to another possible bias: some women will have died in the years between the date for which we want to estimate an IMR and the survey date, so the survey collects no information about them. If these women's infants were more likely to die than infants in general - a reasonable supposition given the importance of HIV in Uganda - then the IMRs estimated for years prior to the survey date will be biased downward, and increasingly so as the lag lengthens. The empirical section tests for this bias and finds that it is not important.

${ }^{4}$ Results for 1995 are omitted to make the graph legible, but they are similar to those shown. Both series are calculated for mother's aged 15-34 only.
} 
Figure 2 - Annual IMRs Calculated for Synthetic and Natural Cohorts

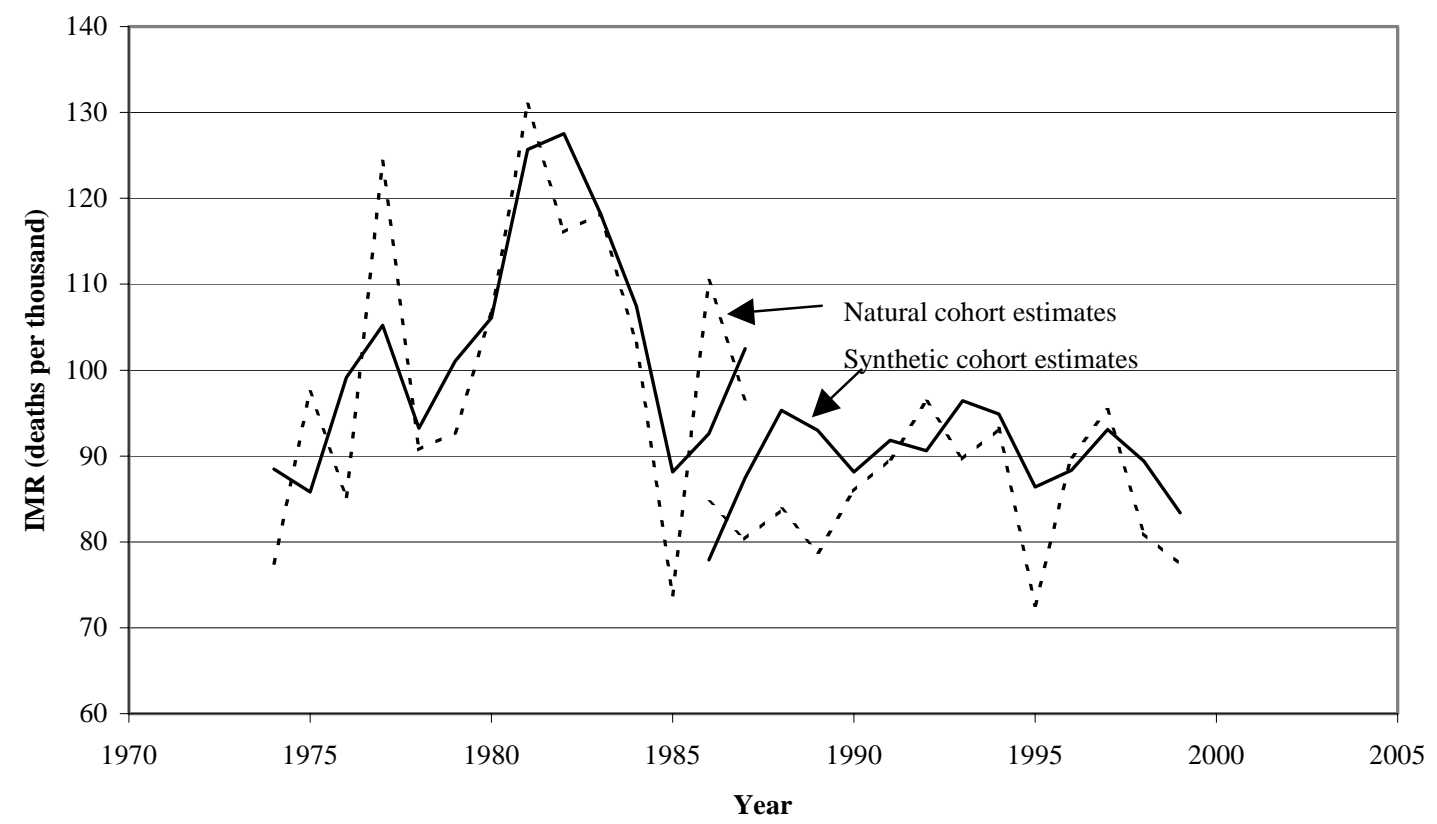

Source: Uganda DHS 1988, 1995, and 2000, and author's calculations

\section{Methods and Data}

We estimate reduced form probit equations of the form

$$
y_{j}=X_{i, j} \beta_{i}+X_{h, j} \beta_{h}+X_{d, j} \beta_{d}+X_{n, j} \beta_{n}+e_{j}
$$

where

$\mathrm{y}_{\mathrm{j}}$ is a $0 / 1$ indicator of whether child $\mathrm{j}$ died before his/her first birthday;

$\mathrm{X}_{\mathrm{i}, \mathrm{j}}$ is a vector of individual-specific variables;

$\mathrm{X}_{\mathrm{h}, \mathrm{j}}$ is a vector of household-specific variables;

$\mathrm{X}_{\mathrm{d}, \mathrm{j}}$ is a vector of district-specific variables;

$\mathrm{X}_{\mathrm{n}, \mathrm{j}}$ is a vector of national variables; and

$\mathrm{e}_{\mathrm{j}}$ is a normally distributed error term.

The data are a sample of infants born to women age 15-34 drawn from the three Uganda DHS surveys. The birth cohorts range from 1973 to 1999. Definitions of the regressors and rationales for their inclusion in the model follow. Table 1 gives descriptive statistics for the UDHS survey data. 
Table 1 - Descriptive Statistics for UDHS Samples in Uganda

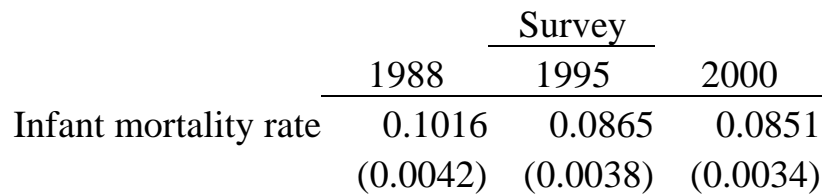

$$
\begin{aligned}
& \begin{array}{llll}
\text { Central } & 0.3193 & 0.3243 & 0.3369
\end{array} \\
& \begin{array}{lll}
(0.0578) & (0.0503) & (0.0527)
\end{array} \\
& \begin{array}{llll}
\text { Eastern } & 0.2799 & 0.2440 & 0.2553
\end{array} \\
& \begin{array}{lll}
(0.0644) & (0.0457) & (0.0482)
\end{array} \\
& \begin{array}{llll}
\text { Northern } & 0.0637 & 0.1147 & 0.1125
\end{array} \\
& \begin{array}{lll}
(0.0359) & (0.0395) & (0.0388)
\end{array} \\
& \begin{array}{llll}
\text { Western } & 0.3371 & 0.3170 & 0.2953
\end{array} \\
& \begin{array}{lll}
(0.0671) & (0.0518) & (0.0484)
\end{array} \\
& \begin{array}{llll}
\text { Rural } & 0.9099 & 0.8707 & 0.8765
\end{array} \\
& \begin{array}{lll}
(0.0189) & (0.0244) & (0.0226)
\end{array} \\
& \begin{array}{lrrr}
\ln (\mathrm{HH} \text { assets }) & 0.2898 & 0.3587 & 0.4291 \\
& (0.0156) & (0.0183) & (0.0194)
\end{array} \\
& \begin{array}{llll}
\text { Surface water } & 0.3388 & 0.2850 & 0.1446
\end{array} \\
& \begin{array}{lll}
(0.0300) & (0.0266) & (0.0191)
\end{array}
\end{aligned}
$$$$
\begin{array}{lrrr}
\text { Piped water } & 0.0256 & 0.0169 & 0.0143 \\
& (0.0066) & (0.0042) & (0.0033)
\end{array}
$$$$
\begin{array}{llll}
\text { Public tap } \quad 0.0413 & 0.0532 & 0.0737
\end{array}
$$$$
\begin{array}{lll}
(0.0098) & (0.0105) & (0.0137)
\end{array}
$$$$
\begin{array}{lrrr}
\text { Well water } & 0.5046 & 0.6359 & 0.7152 \\
& (0.0342) & (0.0259) & (0.0214)
\end{array}
$$$$
\begin{array}{llll}
\text { Other water } & 0.0896 & 0.0091 & 0.0523
\end{array}
$$$$
\begin{array}{lll}
(0.0137) & (0.0020) & (0.0057)
\end{array}
$$

$\begin{array}{llll}\text { Flush toilet } \quad 0.0266 & 0.0171 & 0.0123\end{array}$

$$
\begin{array}{lll}
(0.0081) & (0.0049) & (0.0028)
\end{array}
$$

$$
\begin{array}{lrrr}
\text { Latrine } & 0.8021 & 0.8463 & 0.8284 \\
& (0.0230) & (0.0172) & (0.0170)
\end{array}
$$




$$
\begin{aligned}
& \text { Other toilet } \quad 0.0096 \quad 0.0078 \quad 0.0463 \\
& \begin{array}{lll}
(0.0034) & (0.0025) & (0.0054)
\end{array} \\
& \begin{array}{llll}
\text { No toilet } \quad 0.1617 & 0.1287 & 0.1131
\end{array} \\
& \begin{array}{lll}
(0.0224) & (0.0168) & (0.0148)
\end{array} \\
& \text { Gender } \quad 1.5009 \quad 1.5097 \quad 1.4974 \\
& \begin{array}{lll}
(0.0052) & (0.0050) & (0.0047)
\end{array} \\
& \text { First-born } \quad 0.2064 \quad 0.2129 \quad 0.2100 \\
& \begin{array}{lll}
(0.0044) & (0.0044) & (0.0045)
\end{array} \\
& \begin{array}{llll}
\text { Multiple birth } \quad 0.0292 & 0.0278 & 0.0218
\end{array} \\
& \begin{array}{lll}
(0.0027) & (0.0024) & (0.0021)
\end{array} \\
& \text { Mother had no schooling } \begin{array}{llll}
0.4351 & 0.3321 & 0.2526
\end{array} \\
& \begin{array}{lll}
(0.0211) & (0.0210) & (0.0156)
\end{array} \\
& \text { Mother had some primary } \begin{array}{llll}
0.3286 & 0.3599 & 0.4135
\end{array} \\
& \begin{array}{lll}
(0.0140) & (0.0129) & (0.0121)
\end{array} \\
& \begin{array}{llll}
\text { Mother finished primary } & 0.1596 & 0.1959 & 0.2180
\end{array} \\
& \text { (0.0108) (0.0121) (0.0114) } \\
& \begin{array}{llll}
\text { Mother had some secondary } & 0.0520 & 0.0716 & 0.0752
\end{array} \\
& \begin{array}{lll}
(0.0071) & (0.0070) & (0.0077)
\end{array} \\
& \begin{array}{llll}
\text { Mother finished secondary } & 0.0247 & 0.0406 & 0.0407
\end{array} \\
& \begin{array}{lll}
(0.0045) & (0.0057) & (0.0050)
\end{array} \\
& \begin{array}{llll}
\text { Mother's age } \quad 23.9513 \quad 24.0637 & 24.0286
\end{array} \\
& \begin{array}{lll}
(0.1038) & (0.0990) & (0.0872)
\end{array} \\
& \text { Any vaccination }^{1} \quad 0.7680 \quad 0.7876 \quad 0.8347 \\
& \begin{array}{lll}
(0.0119) & (0.0093) & (0.0068)
\end{array} \\
& \begin{array}{lrrr}
\text { All vaccinations }^{1} & 0.4873 & 0.4602 & 0.4043 \\
& (0.0202) & (0.0142) & (0.0116)
\end{array} \\
& \text { Tetanus toxoid }^{1} \quad 0.5322 \quad 0.7270 \quad 0.7632 \\
& \begin{array}{lll}
(0.0211) & (0.0108) & (0.0073)
\end{array}
\end{aligned}
$$




\begin{tabular}{|c|c|c|c|}
\hline Any professional prenatal care ${ }^{1}$ & $\begin{array}{r}0.9853 \\
(0.0060)\end{array}$ & $\begin{array}{r}0.9426 \\
(0.0038)\end{array}$ & $\begin{array}{r}0.8889 \\
(0.0078)\end{array}$ \\
\hline Any professional birthing help ${ }^{1}$ & $\begin{array}{r}0.4941 \\
(0.0277)\end{array}$ & $\begin{array}{r}0.4780 \\
(0.0166)\end{array}$ & $\begin{array}{r}0.3179 \\
(0.0133)\end{array}$ \\
\hline Use of modern birth control ${ }^{2}$ & $\begin{array}{r}0.0406 \\
(0.0055)\end{array}$ & $\begin{array}{r}0.1134 \\
(0.0112)\end{array}$ & $\begin{array}{r}0.2068 \\
(0.0135) \\
\end{array}$ \\
\hline \multicolumn{4}{|c|}{ Source: UDHS 1988, 1995, and 2000} \\
\hline $\begin{array}{l}\text { Notes: Means, with standard err } \\
\text { rounds of the UDHS and } \\
{ }^{1 /} \text { These variables are dist } \\
{ }^{12} \text { These variables are clus }\end{array}$ & $\begin{array}{l}\text { ors in pare } \\
\text { only for w } \\
\text { rict/year-of } \\
\text { ter average }\end{array}$ & $\begin{array}{l}\text { theses. Da } \\
\text { omen aged } \\
\text {-birth aver }\end{array}$ & $\begin{array}{l}\text { ta are for only those districts surveyed in all three } \\
15-34 \text { at the time of the child's birth. } \\
\text { ges. } \\
\text { e of the survey. }\end{array}$ \\
\hline
\end{tabular}

\subsection{Individual Characteristics}

Boys, first-born children, and children of multiple births typically have higher mortality probabilities, other things equal. The models include a variable for each of these characteristics to control for factors that, while not relevant to policy, may introduce unwanted variation into the model.

Infants of mothers who are older and better educated have lower mortality probabilities, other things equal. The models include mother's age at the child's date of birth and dummies for whether the mother (1) attended primary school, (2) graduated from primary school, (3) attended secondary school, or (4) graduated from secondary school. These educational attainment variables are of interest to policy makers. Uganda made a concerted effort to increase primary school enrolments in 1997 with its Universal Primary Education Program (UPE). UPE abolished school fees at public schools and included a major public relations campaign to encourage all children to attend school. Enrolments did, in fact, increase substantially in the wake of UPE, from 2.6 million primary students in 1996 to 7.3 million in 2002 (Bategeka, et.al, 2004). One future benefit of this increase in enrolments may be healthier children, an hypothesis that this paper examines.

\subsection{Household Characteristics}

\subsubsection{Household assets}

One interest of the paper is to further investigate the lack of correlation between income and infant mortality that is evident in the national data. Uganda has been growing fast, yet infant mortality has not improved. Does the same lack of correlation apply to individual level data, i.e. are infants in richer households no less likely to die than those in poorer households?

Unfortunately, the UDHS surveys do not collect information on income. As a proxy, this paper uses an index of wealth based on a factor analysis of 7 household assets: whether the household owns a radio, television, refrigerator, bicycle, and a motorized form of transport; whether the 
household has a dirt floor (a liability rather than an asset); and the household head's years of education. ${ }^{5}$ Sahn and Stifel (2003) compare the use of this type of wealth index to the more typical expenditures per capita as a regressor in a reduced form model of children's height-forage z-scores. In 12 different samples from 10 developing countries, they find that the wealth index is as good as or better than household expenditures per capita, whether instrumented or not, as a proxy for household well-being. Thus, lack of income or expenditure data in the UDHS may not be a serious limitation for the IMR models estimated here.

\subsubsection{Other Household Characteristics}

In addition to household wealth, regressors include the geographic characteristics - political region where the household lives and whether it lives in an urban or rural area - and characteristics of the household's water supply and sanitation system. ${ }^{6}$

One important limitation of the household data is that they are available only at the time of the survey, not retrospectively. Nevertheless, we apply current values of these variables to all children from the sample, regardless of the year in which they were born. If both infant mortality and household characteristics had trends, this might produce an important downward bias in the coefficients on the household characteristics, since relatively high values of assets and housing characteristics at the time of the survey would be applied to IMRs that occurred years earlier, when the correct values of these variables were lower. However, the fact that IMRs show little trend over time diminishes this concern. Nevertheless, there is clearly the possibility of measurement error, and thus of attenuation bias, for these estimates.

The same limitation applies to houseohld location variables, region and area, which pertain to the date of the survey. To the extent that households have migrated since a child's birth, this information will be inaccurate. In particular, since most immigration is from rural to urban areas, and since infant mortality rates are lower in urban areas, there will be a downward bias on the estimated urban-rural difference in IMR since some infant deaths that occurred when mothers were in rural areas (at the time of birth) will be recorded as urban (at the time of the survey).

\subsection{District Characteristics}

The UDHS surveys include information on prenatal care, birthing assistance, and vaccination of children born in the past five years and their mothers. Vaccinations are directly relevant to infant mortality, while all three variables proxy the availability of health services. To avoid the possible endogeneity that could stem from the joint determination of these health care choices and others that affect mortality probability, these variables are averaged at the district level, by year. Note that including the vaccination data reduces the sample size considerably, from children born up

\footnotetext{
${ }^{5}$ See Sahn and Stifel (2002) or Filmer and Pritchett (2000) for details of this type of index.

${ }^{6}$ Note that these were not included in the asset index so as not to confound their direct effects as promoters of good health with their indirect effects as a proxy for greater economic resources.
} 
to 15 years before the survey date to children born up to five years before the survey date. ${ }^{7}$ For that reason, these regressors are not included in all models. Nevertheless, the obvious importance of these variables for policy makes sacrificing sample size worthwhile for at least some models.

\subsection{Cluster Characteristics}

The UDHS surveys include on additional health care indicator, whether women use a modern form of contraception. As with the district variables, this variable is averaged at the cluster level at the time of the survey, because there is no retrospective information on birth control. In regressions where we use the full 15 year lag off the survey date, this is our only health care variable. We do not interpret its impact on infant mortality literally, but rather suppose that this is proxying for availability of health care in the cluster that we cannot measure.

\subsection{National Characteristics}

The regressions include a quartic time trend to check for correlations between unexplained progress over time in IMRs that may come through once the microeconomic variables are controlled for. In addition, the regressions include an estimate of the national HIV infection rate. The increase and subsequent decline in HIV infections in Uganda is an obvious candidate to explain the increase and decline of infant mortality in the 1980s. Unfortunately, the UDHS surveys did not collect data on HIV infections, so we are limited to a national estimate. Even so, long time series for HIV prevalence in Uganda are not available, so the data include a backcasting of prevalence rates based on an epidemiological model due to Feeney and Zaba (no date). For the period 1985-1999 the series is the reported prevalence for pregnant women using the antenatal clinic at Nsanbya. This is the clinic with the longest available series for HIV prevalence. For 1977-1984, the series is backcast using the Feeney and Zaba model.

\section{Results}

Table 2 gives a basic infant mortality regression and three variants. Note first that the coefficient on the log of household assets has a significantly negative coefficient in all of the models. Thus, unlike the national time series cited in government reports as a cause for concern (UBoS/Macro, 2001; Ministry of Finance, Planning, and Economic Development, 2002), these data do show the expected negative correlation between level of well-being and infant mortality. Nevertheless, the impact is disappointingly small: a doubling of the household asset index would reduce infant mortality by about 21 to 24 deaths per thousand births. This may seem a reasonably large effect, but it is important to recall that the asset index rose by only 14 percent on average in the twelve years between 1988 and 2000, yielding a decline in the average infant mortality probability of only about 3 per thousand. ${ }^{8}$

\footnotetext{
${ }^{7}$ We do recover some additional observations by including children of women up to 44 rather than 34 years old for these regressions, because we are limited to a five year lag only.

${ }^{8}$ The asset index does not grow as rapidly as GDP per capita because it is rescaled and expressed in a -1 to 1 scale rather than in shillings.
} 
The results for basic demographic regressors are all statistically significant and as expected. First-born children have a mortality probability that is about two percent higher than other children. This may seem a small amount, but it is important to interpret the coefficient correctly. The overall infant mortality rate is 90 per thousand births, or nine percent, for this sample. The coefficient indicates that, other things equal, the IMR for first-born children is 109 per thousand births, or eleven percent. Children of multiple births (twins, etc) have a remarkable 200 deaths per thousand births higher infant mortality rate than other children. The other two demographic effects are less dramatic. Girls have a somewhat lower IMR than boys (seven per thousand), ${ }^{9}$ and each year of the mother's age at the child's date of birth lowers the IMR by 1.1 to 1.8 per thousand. All of these results are robust to the variations in models (2)-(4).

Other aspects of the results are more surprising. None of the dummies for the household's water supply or type of toilet facility is statistically significant, nor are they jointly significant in any of the models. ${ }^{10}$ Even more surprisingly, none of the regional or urban/rural dummies is significant in any of the models. We return to these findings below.

\footnotetext{
${ }^{9}$ Note that a model interacting gender with all the regressors produces no significant interactions other than the constant, which the dummy variable in these models picks up.

${ }^{10}$ Rutstein (2000) found similar results for a cross-country analysis. Strauss and Thomas' (1995) review of the literature on health production functions notes that it is not uncommon to find that household water supply and toilet facility are not correlated with children's health variables. One possible explanation for this is that supposedly clean water sources like piped water or protected wells may not, in fact, be uncontaminated, nor are all latrines equally sanitary.
} 
Table 2 - Infant Mortality Regressions for Uganda

(1)

Coefficient t-statistic

Variable

\begin{tabular}{|c|c|c|c|c|c|c|c|c|}
\hline & & & & & & & 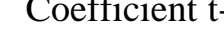 & \\
\hline Eastern region & 0.0033 & 0.62 & 0.0040 & 0.73 & 0.0061 & 0.85 & 0.0034 & 0.63 \\
\hline Northern region & 0.0012 & 0.18 & -0.0011 & -0.17 & -0.0060 & -0.72 & 0.0018 & 0.27 \\
\hline Western region & -0.0006 & -0.11 & -0.0028 & -0.50 & 0.0083 & 1.16 & 0.0001 & 0.01 \\
\hline Rural & -0.0072 & -0.94 & -0.0047 & -0.59 & -0.0110 & -1.14 & -0.0072 & -0.95 \\
\hline $\ln (\mathrm{HH}$ assets $)$ & -0.0228 & -2.80 & -0.0222 & -2.69 & -0.0211 & -2.24 & -0.0227 & -2.79 \\
\hline Piped water & 0.0029 & 0.18 & 0.0014 & 0.08 & 0.0042 & 0.23 & 0.0029 & 0.18 \\
\hline Public tap & -0.0073 & -0.90 & -0.0058 & -0.68 & -0.0137 & -1.33 & -0.0073 & -0.89 \\
\hline Well water & -0.0053 & -1.17 & -0.0068 & -1.51 & -0.0037 & -0.64 & -0.0053 & -1.17 \\
\hline Other water & -0.0016 & -0.18 & 0.0018 & 0.18 & 0.0157 & 1.07 & -0.0011 & -0.12 \\
\hline Flush toilet & -0.0096 & -0.65 & -0.0087 & -0.56 & -0.0226 & -1.26 & -0.0089 & -0.61 \\
\hline Latrine & -0.0038 & -0.72 & -0.0035 & -0.63 & -0.0089 & -1.22 & -0.0040 & -0.75 \\
\hline Other toilet & -0.0192 & -1.00 & -0.0169 & -0.86 & 0.0154 & 0.59 & -0.0187 & -0.97 \\
\hline Female & -0.0076 & -1.96 & -0.0072 & -1.82 & -0.0070 & -1.61 & -0.0076 & -1.95 \\
\hline First-born & 0.0191 & 3.85 & 0.0178 & 3.49 & 0.0230 & 3.50 & 0.1229 & 3.49 \\
\hline Multiple birth & 0.1998 & 14.17 & 0.1990 & 13.83 & 0.2197 & 11.08 & 0.2001 & 14.19 \\
\hline Mother attended primary & -0.0084 & -1.82 & -0.0082 & -1.80 & -0.0024 & -0.40 & -0.0085 & -1.84 \\
\hline Mother finished primary & -0.0196 & -3.74 & -0.0193 & -3.66 & -0.0136 & -1.88 & -0.0195 & -3.72 \\
\hline Mother attended secondary & -0.0344 & -4.52 & -0.0338 & -4.33 & -0.0296 & -2.89 & -0.0340 & -4.44 \\
\hline Mother finished secondary & -0.0344 & -3.17 & -0.0348 & -3.20 & -0.0260 & -1.92 & -0.0320 & -2.87 \\
\hline Mother's age & -0.0016 & -4.07 & -0.0018 & -4.24 & -0.0011 & -2.58 & -0.0013 & -3.04 \\
\hline Mother's age X first-born & & & & & & & -0.0041 & -2.84 \\
\hline Use of modern birth control /1 & -0.0348 & -2.02 & -0.0309 & -1.58 & -0.0052 & -0.26 & -0.0348 & -2.02 \\
\hline Time trend 2/ & & & 0.0645 & 0.16 & & & & \\
\hline (Time trend) $^{\wedge 2} 2 /$ & & & -0.0028 & -0.18 & & & & \\
\hline (Time trend) ${ }^{\wedge 3} 2 /$ & & & 0.0001 & 0.19 & & & & \\
\hline (Time trend) $^{\wedge 4} 2 /$ & & & 0.0000 & -0.20 & & & & \\
\hline $\begin{array}{l}\text { National HIV prevalence } 2 / \\
\text { Years born before survey }\end{array}$ & & & 0.0144 & 0.21 & & & & \\
\hline Any vaccination received 3/ & & & & & 0.0170 & 0.73 & & \\
\hline All vaccinations received 3/ & & & & & -0.0324 & -2.19 & & \\
\hline Tetanus toxoid received 3/ & & & & & -0.0243 & -1.74 & & \\
\hline Prenatal care received 3/ & & & & & -0.0297 & -1.39 & & \\
\hline Prof. birth assistance 3/ & & & & & -0.0008 & -0.07 & & \\
\hline Constant & -0.8523 & -8.42 & -4.17 & -0.17 & -0.66 & -2.75 & -0.92 & -8.86 \\
\hline Sample size: & & 33,847 & & 32,288 & & 19,008 & & 33,847 \\
\hline
\end{tabular}

Source: Uganda DHS 1988, 1995, 2000, and author's calculations

Notes: All coefficients except that for the constant are marginal effects evaluated at the regressors' means. For discrete regressors, they are the difference in the probability of mortality evaluated at 0 and 1.

All t-statistics are based on standard errors that account for the clustered survey design.

$1 /$ These variables are cluster averages at the time of the survey.

$2 /$ These variables are national at the time of birth.

$3 /$ These variables are district averages at the time of birth. 
Mother's education has a significant impact on infant mortality, and the reduction is larger for mothers with more education. Mortality rates for infants whose mother is a primary graduate are 20 per thousand lower than those whose mother did not complete primary school. For the infants of mothers who attended or completed secondary school or higher, mortality rates are 34 per thousand lower. Unlike the other regressors, however, the coefficients on these variables are sensitive to the reduction in sample size in model (3). The coefficient for mothers with only incomplete primary education declines especially sharply and is no longer statistically significant. $^{11}$

Finally, as a proxy for the availability of health care services, the models include the district share of women using a modern method of birth control at the time of the survey. This variable has a large mean impact, 31-35 per thousand, but it is only marginally significant, perhaps because the district averages do not have much variation. The coefficient on this variable is also much smaller in model (3), a point we return to below.

Model (2) in Table 2 includes two variables that have only time-series variation: an estimated HIV prevalence rate for Uganda as a whole, and a fourth-order polynomial time trend. The coefficient on HIV prevalence has the right sign, but it has a huge standard error so that it is indistinguishable from zero. Even the coefficient is small: reducing national HIV prevalence from twelve percent, its rate in 2000, to zero, would only reduce infant mortality by about 1.5 deaths per thousand. Of course, we should recognize that the HIV data used here are extremely crude, which may explain the lack of any interesting correlation. ${ }^{12}$ What's more, Table 1 shows improvements in some regressors that have a beneficial impact on infant mortality (assets, multiple births, mother's education, and access to modern contraception), but it does not show dramatic changes over time in any of the regressors that might help to explain why infant mortality did not decline more during the 1990s. Thus, the long-term stagnation of the IMR shown in Figure 1 remains a puzzle.

The time trend is also insignificantly different from zero, with an $\mathrm{F}_{5,487}=0.27$, and its overall effect is also small. From its maximum in 1976, the trend only accounts for a decline of 16 deaths per thousand by the year 2000, less than one death per thousand per year. Thus, unlike many other indicators of social progress, there does not appear to be an unexplained trend improvement in infant mortality in Uganda.

As noted in the data and methods section, one of the weaknesses of the data used in this paper is that many independent variables are available only at the time of the survey, while the dependent variable is available annually for fifteen years (or more) prior to the survey. As a check on the importance of using long lags for the IMR, we estimated model (1) including a variable for the number of years before the relevant survey that an infant was born. If it is the case that the women who died between a given year and the survey date, and were thus not surveyed, also had

\footnotetext{
${ }^{11}$ The conclusion that this depends on the sample rather than the inclusion of the vaccination variables comes from the fact that the same model on the smaller sample without the vaccination variables yields almost the same coefficients on the mother's education variables as shown in column (4), and from the fact that the correlation between mother's education and district-level vaccination rates is almost zero.

${ }^{12}$ Further experimentation with larger sets of macroeconomic variables such as real GDP per capita and national vaccination rates produced similar results: none of these regressors was significant.
} 
infants more likely to die (say, because of HIV), then their exclusion from the sample should cause a downward bias in the estimated infant mortality rate for years before the sample, and that bias should be greater with longer lags. However, the coefficient on the additional variable is tiny -- less than one per thousand per year -- and insignificantly different from zero, indicating that there does not seem to be too much bias coming from the possibility that mother's who have died before the survey date also had infants with higher mortality probability. In addition, we interacted all the regressors in model (1) with the years lag variable. None of the interactions is significantly different from zero, individually or jointly. Thus, the fact that some regressors are available only at the time of the survey also may not be too problematic. ${ }^{13}$

Model (3) includes district/year average health indicators for children and their mothers. There are two vaccination variables, one for having received any vaccination, and one for having received all the recommended childhood vaccinations. There is also an indicator as to whether a child's mother received a tetanus toxoid injection during her pregnancy with that child, whether she received any prenatal care from a health professional, and whether she received any birthing assistance from a health professional.

The variable for any vaccination has the wrong sign, but its coefficient is smaller and it is insignificantly different from zero. The variable for all vaccinations is positive and significant, however. Taking the two together (because one cannot receive all vaccinations with receiving at least one), if district average vaccination rates increased from zero to one, each infant's mortality probability would decline by 1.5 percentage points, or 15 deaths per thousand. The tetanus toxoid indicator has a relatively large impact, 24 deaths per thousand, but it is only significant at the 10 percent level. The variables for the other health care indicators are insignificantly different from zero at standard levels, perhaps because of a relatively higher correlation between all of these variables, but the coefficient on prenatal care is also large. Note that including these variables reduces the coefficient on modern contraceptive use, a result that makes sense if the latter is indeed proxying for availability of health care services important for infant's survival in the other regressions.

Model (4) explores another concern in reproductive health in Uganda, the high incidence of teenage pregnancy. It is common to find that infant mortality is higher for children of younger mothers, a result in all our models as well. Thus, delaying births, and especially first births, might help to reduce infant mortality. To explore this possibility, Model (4) interacts the mother's age with a dummy variable for first-born children, thus capture mother's age at first birth. This variable is negative, significantly different from zero, and actually much larger than the coefficient on mother's age at birth. Infant mortality declines by four deaths per thousand for each year that a first birth is delayed. As Figure 3 shows, almost half of Ugandan mothers give birth to their first child before they reach 18 years old, the age of consent in Uganda, so it appears possible to reduce infant mortality in Uganda by reducing teen pregnancy.

That appearance is, however, illusory. The coefficient on the the mother's age-first child interaction is non-zero only for first children, who are only 21 percent of the sample. Of that 21 percent, a little less than half are children born to mothers less than 18 years old so, in effect, postponing first teen pregnancies affects only about 10 percent of births in Uganda. So the

\footnotetext{
${ }^{13}$ These regression, not reported here, are available upon request.
} 
impact of a one-year postponement in first pregnancies for teenagers younger than 18 is only 0.4 deaths per thousand per year when averaged over all births. Even assuming that all pregnancies are delayed for women whose first pregnancy occurs before she is 18 has only a very small impact on overall infant mortality, as we show below.

\section{Figure 3 - Frequency distribution of mother's age at birth of first child}

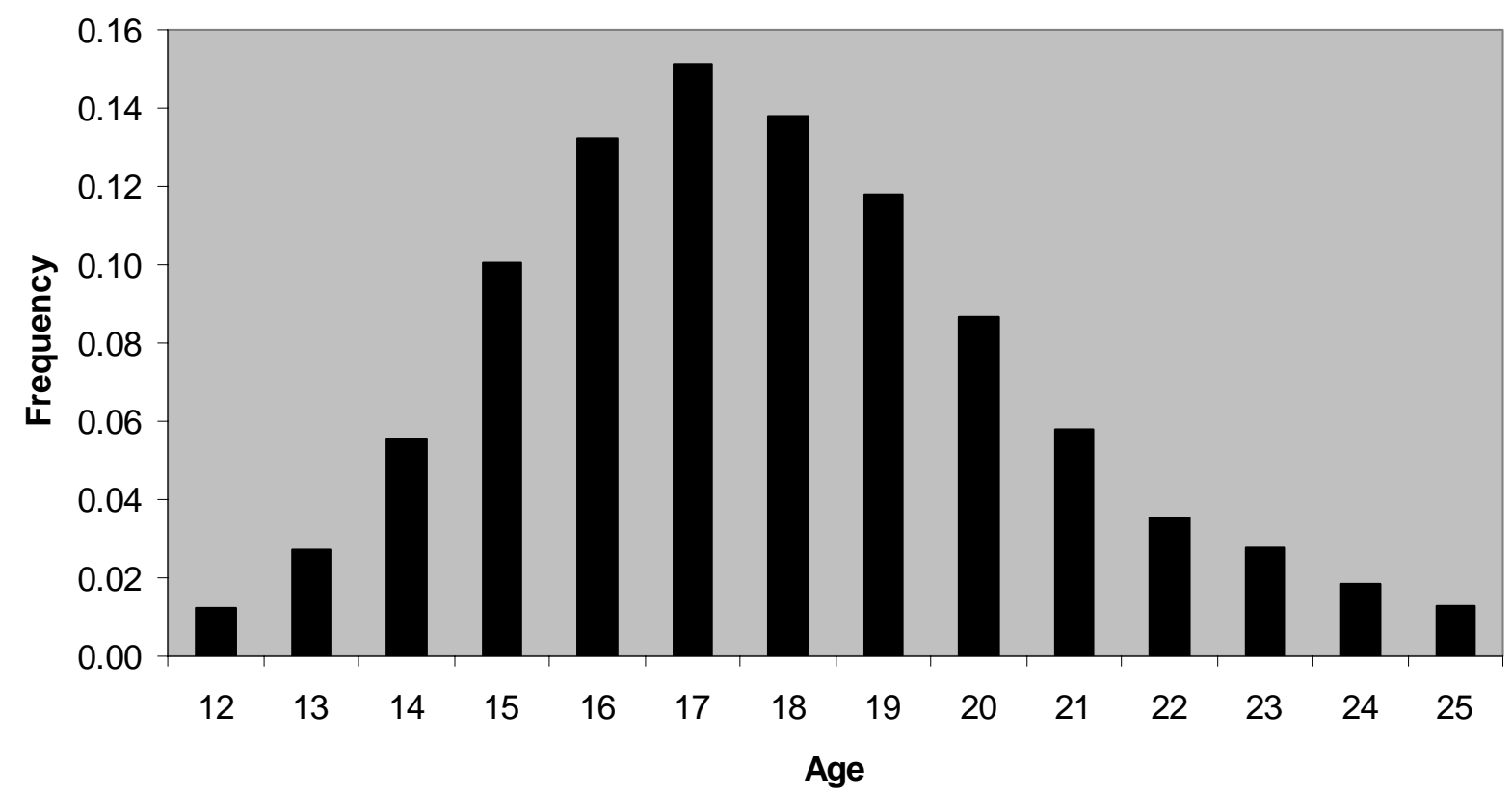

Source: UDHS 1988, 1995, 2000 and authors' calculations

Notes: Data are for only those districts surveyed in all three rounds of the UDHS.

Earlier we noted that the regional variables are not significant in any regressions. This is not to say, however, that there are not significant regional differences in IMRs in Uganda, because these estimates are conditional on the other regressors. Table 3 shows simple regressions of infant mortality on region and area (urban/rural) only, model (5), and then adds household assets, model (6). In model (5), both the regional and area variables are clearly significant. Infants in Eastern, Northern, and Western regions are 1.1, 1.4, and 0.8 percent more likely to die before their first birthday than are infants in Central region. Again, keeping in mind that the overall IMR is nine percent, these are large differences. The urban/rural difference is larger still: infants in rural areas are 2.0 percent more likely to die than those in urban areas. 
Table 3 - IMR regressions on Region, Area, and Assets Only

\begin{tabular}{rrrrr}
\hline & \multicolumn{2}{c}{$(5)$} & \multicolumn{2}{c}{$(6)$} \\
coefficient & t-statistic & coefficient & t-statistic \\
\hline Eastern & 0.0112 & 2.32 & 0.0061 & 1.24 \\
Northern & 0.0142 & 2.13 & 0.0071 & 1.06 \\
Western & 0.0083 & 1.91 & 0.0022 & 0.50 \\
rural & 0.0198 & 4.74 & 0.0016 & 0.30 \\
$\ln$ (HH assets) & & & -0.0422 & -6.51 \\
\hline
\end{tabular}

Source: Uganda DHS 1988, 1995, 2000, and author's calculations

Notes: All coefficients are marginal effects.

Model (6) is interesting because it adds only the log of household assets to model (5), yet this produces huge changes in the coefficients for the regions and rural areas, to values much closer to those found in Table 2. Furthermore, the coefficients on the regions and on the rural dummy are no longer significantly different from zero, individually or jointly. Thus, it seems that variation in household assets, or more generally, well-being, across regions and area largely account for the differences in the observed infant mortality rates in Uganda.

We repeated this exercise for the water and sanitation variables, reported in Table 4. As with the regional variables, these variables are correlated with infant mortality, and in the direction that one would expect. In model (7), children living in households with access to piped water in their home or to a public tap have an infant mortality rate that is 25 per thousand lower than children in households using surface sources (lakes and rivers, the default category). Those with flush toilets and latrines have an infant mortality rate that is 31 and 13 per thousand lower, respectively, than children in households with no toilet. But again, model (8) shows that most of these correlations become smaller and insignificantly different zero when conditioned on household assets. ${ }^{14}$

Table 4 - IMR regressions on Water Source, Sanitation, and Assets Only

\begin{tabular}{lrrrrr}
\hline & \multicolumn{2}{c}{$(7)$} & & \multicolumn{2}{c}{$(8)$} \\
& coefficient & t-statistic & & coefficient & t-statistic \\
\cline { 2 - 3 } \cline { 5 - 6 } Piped water & -0.0247 & -2.36 & & 0.0024 & 0.19 \\
Public tap & -0.0252 & -3.88 & & -0.0103 & -1.41 \\
Well & -0.0111 & -2.73 & & -0.0084 & -2.06 \\
Other water & -0.0014 & -0.16 & & 0.0006 & 0.07 \\
Flush toilet & -0.0317 & -2.86 & & -0.0173 & -1.42 \\
Latrine & -0.0132 & -2.52 & & -0.0070 & -1.35 \\
Other toilet & -0.0162 & -1.30 & & -0.0213 & -1.10 \\
ln(HH Assets) & & & & -0.0411 & -6.69 \\
\hline
\end{tabular}

Source: Uganda DHS 1988, 1995, 2000, and author's calculations Notes: All coefficients are marginal effects.

\footnotetext{
${ }^{14}$ Note that the asset index does not include water and sanitation characteristics of the household.
} 
Finally, we close this section by noting that models similar to those shown here, but estimated on larger samples, yield very similar results. In particular, whether we limit the sample to women age 15-34 and to the districts that are comparable in all three UDHS surveys has little effect on the results.

\section{Achieving the Millennium Development Goal - Simulations}

One of the Millennium Development Goals (MDGs) is to reduce under-five mortality by twothirds between 1990 and 2015. This paper uses infant rather than under-five mortality because it allows for significantly larger and more relevant samples. To avoid censoring children who are not yet five, an analysis of under-five mortality would need to discard data for the children born within five years before the survey date, rather than one year in the case of infant mortality. Among other problems, this would preclude an analysis of the impact of vaccinations on mortality because the latter are available only for children born within five years of the survey date. To make our analysis relevant to the MDG, then, we apply the same goal of a two-thirds reduction in infant mortality between 1990 and 2015, a goal that policy makers in Uganda have already accepted (Ministry of Finance, Planning, and Economic Development, 2002). In Uganda's case, this goal implies a reduction from about 90 per thousand in 1990 to about 30 per thousand in 2015. However, given that there is little evidence of improvement between 1990 and 2000 , it is actually necessary to achieve the entire reduction of 60 deaths per thousand in the short period of 2000-2015. Is this possible?

We have already seen that there is no hope that a general trend improvement in IMRs will help to achieve the MDG. The trend is simply too flat to make much difference in a fifteen-year time period. However, some of the regressors that do have significant effects on the probability of infant mortality have been improving over time, and can reasonably be expected to continue to improve. Table 5 shows that household assets and mother's educational attainment have increased significantly over the 12 years from 1988 to 2000. On the other hand, except for the share of pregnant women receiving at least one tetanus toxoid injection, basic indicators of health care for pregnant mothers and infants have fallen somewhat during this period, to the detriment of progress on infant mortality. Nevertheless, the recent substantial increases in public health expenditures should help to reverse these trends. Improvement in these income, education, and health variables may help Uganda to achieve the MDG for infant mortality. 
Table 5 - Descriptive Statistics for Selected Regressors in Model (3)

\begin{tabular}{rrrr} 
& \multicolumn{2}{c}{ Survey } & \\
\cline { 2 - 3 } $\ln ($ HH assets $)$ & 1988 & 1995 & 2000 \\
\hline & 0.2913 & 0.3549 & 0.4246 \\
$(0.0155)$ & $(0.0176)$ & $(0.0191)$
\end{tabular}

$$
\begin{array}{rrrr}
\text { Mother had some primary } & 0.3371 & 0.3688 & 0.4172 \\
& (0.0132) & (0.0127) & (0.0122) \\
& & & \\
\text { Mother finished primary } & 0.1680 & 0.1927 & 0.2135 \\
& (0.0112) & (0.0116) & (0.0113)
\end{array}
$$

$\begin{array}{llll}\text { Mother had some secondary } \quad 0.0526 & 0.0702 & 0.0730\end{array}$

$\begin{array}{lll}(0.0070) & (0.0065) & (0.0078)\end{array}$

$\begin{array}{lrrr}\text { Mother finished secondary } \quad 0.0286 & 0.0378 \quad 0.0407\end{array}$

$\begin{array}{lll}(0.0053) & (0.0054) \quad(0.0051)\end{array}$

Any vaccination $\quad 0.7701 \quad 0.8240 \quad 0.8860$

$\begin{array}{lll}(0.0117) & (0.0070) & (0.0055)\end{array}$

All vaccinations $\quad 0.4908 \quad 0.4982 \quad 0.4628$

$\begin{array}{lll}(0.0207)(0.0148) & (0.0133)\end{array}$

Tetanus toxoid $\quad 0.5299 \quad 0.7290 \quad 0.7764$

$\begin{array}{lll}(0.0213) & (0.0110) & (0.0077)\end{array}$

Any professional prenatal care $\quad 0.9861 \quad 0.9362 \quad 0.8822$

Source: UDHS 1988, 1995, and 2000.

$\begin{array}{lll}(0.0055) & (0.0039) \quad(0.0089)\end{array}$

Notes: Means, with standard errors in parentheses. Values are not identical to Table 1 because that table uses all available observations while this one uses only those observations with all the data necessary to be included in model (3).

This section evaluates the extent to which these variables, each clearly related to public policy choices, might lower infant mortality probabilities by 2015. Unlike the interpretation of the regression results, here we model a given change in an exogenous variable for each infant in the sample and then report the mean change in predicted mortality probability for the sample. ${ }^{15}$ All of the simulations use model (3) from Table 2 to allow us to include simulations involving the basic health care variables.

\footnotetext{
${ }^{15}$ The marginal effects reported in Table 2 are calculated once, for the mean values of the regressors.
} 


\subsection{Household Assets}

The regression results find that there is, in fact, a correlation between household assets, which we take as a proxy for economic well-being, and infant mortality. This leads to some hope that Uganda's impressive economic progress will also lead to better health outcomes. Unfortunately, those hopes are largely misplaced. The annual rate of improvement in the asset index was 0.81 percent per year. Projecting this increase from 2000 to 2015 and simulating the effect of this improvement on the average mortality probability for infants in the sample yields a decline of only 2 infant deaths per thousand births, from 86 to 84 . Thus, holding all else constant, continued improvement in households' economic well-being alone will not get Uganda anywhere close to its MDG for infant mortality.

\subsection{Vaccinations}

One proposed explanation of the lack of progress on infant and child mortality in Uganda has been a decline in vaccinations, especially in the late 1990s. Overall, the share of fully immunized children fell from 47\% in 1995 to 37\% in 2000 (Moller, 2002). ${ }^{16}$ This decline has been attributed to a variety factors in policy discussions, including: lack of political support for vaccinations at all levels; and a decline in popular support for the national immunization programme; and decentralization. This latter effect may have occurred as responsibility for vaccinations became less clear as health service delivery was moved from the central to the district governments. Improving vaccination rates is now an important goal for the Ministry of Health, which has initiated a program of revitalization of Uganda National Expanded Program on Immunization (UNEPI). If we assume that vaccination coverage is complete by 2015, then the decline in the average predicted probability of mortality is substantial, 14 deaths per thousand, but still far from sufficient to achieve the MDG.

\subsection{Health Care}

In addition to declining vaccination rates, Table 5 shows that other indicators of basic health care coverage for pregnant women and infants have worsened over the 1990s for our sample. We suppose that these trends can be reversed so that tetanus toxoid and prenatal care coverage, the two variables with large coefficients in Model (3), are 100 percent in 2015. The impact of these improvements is substantial, 9 deaths per thousand, especially considering that their coverage is already relatively high in 2000 .

\subsection{Teen Pregnancy}

As discussed above, there is concern that teenage pregnancy is an important contributor to overall infant mortality in Uganda, but our results do not support that conjecture. Here, we make the following simulation: if a woman's first birth occurs before she is 18 years old, we increase

\footnotetext{
${ }^{16}$ Note that the decline in our sample is not nearly so severe.
} 
the age at which all of her children are born by the difference between 18 and the actual age at which she first gave birth. So, for example, if a woman gave birth at ages 15, 17, and 25, we change these to 18,20 , and 28 . This is clearly a very optimistic simulation with regards to teen pregnancy. Even so, we find that this reduces overall infant mortality by only 2 deaths per thousand in Uganda. Thus, whatever the other benefits of reduced teen pregnancy, especially with respect to girls' educational attainment and health, it will not reduce infant mortality appreciably.

\subsection{Mother's Educational Attainment}

Uganda has made extraordinary strides in primary school attendance. With the advent of the UPE in 1997, school attendance increased significantly. In 1992, net enrolment rates for children ages six to twelve were 61 percent, while in 1999 the rate rose to 83 percent. Further, despite concerns that large class sizes might affect the quality of education and thus discourage attendance, enrolments rates maintained these gains up to 2003, when 85 percent of children in this age group were attending school. What's more, gains for girls were somewhat larger than those for boys. In 1992, 59 percent of girls of primary school age attended school, while 64 percent of boys did. By 2003, girls had achieved parity, with 85 percent of both girls and boys attending. Thus, our first simulation supposes that by 2015, all mother's will have at least attended some primary school, an assumption that seems quite conservative. The impact of this improvement is small, however, only 1 death per thousand, because the coefficient on mothers having attended, but not finished, primary schooling is low.

If we simulate all mothers in 2015 having graduated from primary school, the result is much better, with a reduction of 9 deaths per thousand. Thus, it seems clear that for the purposes of reducing future infant mortality, simply getting girls to into primary school, a main goal of UPE, is not nearly as important as ensuring that they graduate. In this light, recent reports that only a small proportion of the first cohort of UPE primary students sat for the primary leaver's exams highlight an important worry for policy makers.

To simulate the effect of secondary schooling on infant mortality, suppose that the 2015 graduation rate for secondary school is the same as the 2000 primary graduation rate, 21 percent. The first cohort of primary graduates under UPE was in 2003. Despite fears that the available secondary schools in the country may not be able to accommodate the increasing number of primary graduates as secondary students in the future (see Bategeka et al, 2004), this seems an entirely plausible projection. The resulting improvement in average infant mortality probability is a modest reduction of 4 deaths per thousand, mostly because the simulated increase in graduation rates is also modest (17 percent).

\subsection{Summary}

Table 6 summarizes these simulations. Clearly, even if Uganda gets many policies right, it will fall short of the MDG for infant mortality. The task is complicated by the fact that some of these policies would have to begin immediately. Having more mothers be primary graduates in 2015, 
for example, requires enrolling girls today. Ensuring that more infants have access to health care cannot be achieved overnight in the future; the process must be started now. Thus, even in the best of circumstances, it seems that Uganda will not achieve this MDG.

Table 6 - Summary of simulated reductions in infant mortality rates

\begin{tabular}{|c|c|c|}
\hline Policy Change & $\begin{array}{l}\text { Predicted } \\
\text { IMR } \\
\text { Reduction }\end{array}$ & $\begin{array}{c}\text { MDG } \\
\text { Target } \\
\text { Reduction }\end{array}$ \\
\hline Household assets increase at present rate to 2015 & 2 & \\
\hline Vaccination rates increase to 100 percent & 14 & \\
\hline Basic mother and infant health coverage improves to 100 percent & 9 & \\
\hline All mothers are primary graduates & 9 & \\
\hline Mothers that are secondary graduates rise to $21 \%$ & 4 & \\
\hline Total: & 38 & 60 \\
\hline
\end{tabular}

The table also indicates where policy can have the greatest impact on infant mortality. General economic growth has only a minor impact on infant mortality rates. Achieving 100 percent vaccination coverage, 100 percent basic health care coverage for pregnant women, and 100 percent primary graduation rates for mothers all have larger impacts. Of these, vaccinations and tetanus toxoid injections have the largest impact and are probably the cheapest to provide, so they offer the most cost-effective way to reduce infant mortality. But even 100 percent coverage on all the basic health services is far from sufficient to achieve the MDG.

\section{Discussion}

This paper addresses two important issues concerning infant mortality rates in Uganda: the paradox of rapidly increasing incomes coinciding with flat infant mortality rates in the 1990s, and the possibility of achieving the Millennium Development Goal for infant mortality, and the extent to which a variety of health and education policies might help to reach that goal. Our success regarding the first of these has been quite limited. Despite controling for a variety of individual, household, cluster, and district effects, we do not find any significant correlations between infant mortality rates and national time series variables such as HIV infection rates, GDP per capita, national vaccination rates, or even a polynomial time trend. What's more, most of the micro-level regressors that have a significant impact on infant mortality improved during the period in which infant mortality rates stagnated. Thus, the paradox of rapid growth coinciding with stagnant infant mortality rates remains unexplained at a national level.

Our results in regard to the second issue are much more useful, if discouraging. The regressions in Table 2 identify several policy variables that have significant correlations with infant mortality, including an index of household wealth, a proxy for household resources; mother's educational attainment; district-level vaccination rates; and district-level access to modern contraception. These latter two are proxies for health care services more generally, with the former perhaps more child-centered. Our simulations suggest that plausible improvements in all 
of these except the household wealth index can have an important impact on infant mortality in Uganda by 2015. Increasing vaccination rates to 100 percent would have the largest, and probably most cost-effective, impact, reducing infant mortality by 14 deaths per thousand births. Increasing access to basic health care for pregnant women also has a substantial impact, 9 deaths per thousand. Given the strong impact of basic health care services on infant mortality rates, it is discouraging to note that the provision of public health services was rather stagnant during the 1990s. Public expenditure on health did increase substantially during this period, from 1.6 in 1990 to 3.4\% in 2001 (UNDP, 2003), aided by significant donor support. However, the rate of improvement in actual service delivery has been below expectations. (UPPAP, 2002; Republic of Uganda, 2003).

Among the education variables, simply enroling more girls in school now has little impact, but ensuring that all girls graduate from primary school will reduce their children's IMR by 9 per thousand when they become mothers. Achieving 100 percent secondary graduation would have an even larger impact, but that does not seem attainable by 2015. Our more modest simulation of increasing the secondary graduation rates among (future) mothers to 21 percent, the current primary graduation rate, yields a much smaller improvement of 4 fewer deaths per thousand. More broadly, even with improvements in all of these areas of public policy, we project that infant mortality would decline by 38 per thousand by 2015, far short of the 60 per thousand necessary to achieve the MDG.

It is possible, however, that our results are too pessimistic. Most of our regressors are proxies: assets proxy for household economic resources; mother's years of education proxy for mother's ability to acquire and use information on child health; district average access to modern contraception proxies health care in general, etc. As such, these variables may suffer from considerable measurement error which may bias our estimates. While it is not possible to say which way this bias goes, many analysts presume that it is toward zero, i.e. a smaller absolute value. ${ }^{17}$ If this is the case, then improvements in assets, mother's education, and access to health care could have larger effects than those that we have estimated, and the simulations in Table 6 would be too pessimistic.

At the same time, however, there are reasons to suspect biases in the opposite direction, toward over-estimate of the parameters. The most important of these is that our regressors may proxy for more effects than the one we intend. District vaccination rates may pick up the general state of health care for infants, for example, if places that have high vaccination rates also have better general health services for infants. If this is the case, then simply increasing vaccination rates, which is relatively simple and inexpensive, would not generate as large an impact on infant mortality as that estimated in Table 2 if the unobserved health service characteristics that are correlated with vaccination rates in our sample do not also improve. The same could be said for many of our other regressors.

Overall, then, while we recognize several possible sources of bias in our estimates, we have no firm reason to believe that the overall effect of such biases is positive or negative. We conclude, then, by noting that if Uganda is to achieve this goal, policy makers will need to redouble their

\footnotetext{
${ }^{17}$ This is because it is possible to prove that the bias is towards zero if there is only one regressor and it is measured with error.
} 
efforts to reduce infant and child mortality, with special attention to discerning the most costeffective interventions available. 


\section{7. $\quad$ References}

Appleton, Simon, 2001, “Changes in Poverty and Inequality,” in Reinikka, Ritva, and Paul Collier, Uganda's Recovery: The Role of Farms, Firms, and Government. Washington, DC: The World Bank.

Appleton and Ssewanyana, 2003, "Poverty analysis in Uganda," 2002/03, Economic Policy Research Centre, Mimeo.

Bategeka, L., M. Ayoki and A. Mukungu , 2004. Financing Primary Education for All: Uganda, Economic Policy Research Centre, Kampala.

Feeney and Zaba (no date), http://gfeeney.com/aidsmodel/ .

Filmer, D., \& Pritchett, L., 2000, "Estimating wealth effects without expenditure data - or tears: An application of educational enrollment in states of India,” Mimeo. The World Bank, Washington, DC.

Katende, C. and N.M. Tumwesigye (2002) 'Factors associated with persistent high infant mortality in Uganda: Analysis from 1995 and 2000 UDHS data', Mimeo, Ministry of Finance, Planning and Economic Development, Kampala.

Moller, C.L., 2002. "Infant Mortality in Uganda1995-2000: Why the non-improvement,” Uganda Heath Bulletin, v.8 (3/4): 211 - 214.

Ministry of Finance, Planning, and Economic Development, 2002, Infant Mortality in Uganda, 1995-2000: Why the Non-Improvement? Kampala: Ministry of Finance, Planning, and Economic Development.

2003, Task Force Report on Infant

and Maternal Mortality in Uganda. Kampala: Ministry of Finance, Planning, and Economic Development.

Mosley,W. H., Chen, L. C. 1984, "An analytical framework for the study of child survival in developing countries," Population and Development Review 10(Supplement): 25-45.

Ntozi, P.M and I.M. Nakanaabi, 1997, "The AIDS epidemic and Infant Mortality in Six Districts of Uganda”, Health Transition, Supplement to Vol. 7,: 189-205.

Okuonzi, S., 2002, “Infant Mortality:Litmus Test of Uganda’s Development”, Uganda Health Bulletin, 8(3/4).

Republic of Uganda (2003), Background to the Budget financial year 2003/04, Ministry of Finance, Planning and Economic Development, Kampala. 
Rutstein, Shea Oscar, 1983, "Infant and Child Mortality: Levels, Trends and Demographic Differentials," WFS Comparative Studies No. 24, Voorburg, the Netherlands: International Statistical Institute.

, 2000, "Factors associated with Trends in Infant and Child Mortality in Developing Countries during the 1990s”, Bulletin of the World Health Organization, 78(10): $1256-1270$.

Sahn, David, and David Stifel, 2003, "Exploring Alternative Measures of Welfare in the Absence of Expenditure Data,” Review of Income and Wealth 49(4): 463-489.

Sahn, David, and David Stifel, 2002, "Poverty Comparisons Over Time and Across Countries in Africa,” World Development 28(12): 2123-2155.

Somoza, Jorge L., 1980, "Illustrative Analysis: Infant and Child Mortality in Colombia," WFS Scientific Reports No. 10, Voorburg, the Netherlands: International Statistical Institute.

Strauss, John, and Duncan Thomas, 1995, "Empirical Modeling of Household and Family Decisions," Chapter 34 in Jere Behrman and T.N. Srinivasan, eds., The Handbook of Development Economics, Volum IIIa, Amsterdam: North Holland.

Uganda Bureau of Statistics and ORC Macro, 2001. Uganda Demographic and Health Survey 2000-2001. Calverton, MD: Uganda Bureau of Statistics and ORC Macro

UPPAP, 2000, Uganda Participatory Poverty Assessment Report. Kampala: Ministry of Finance and Economic Planning.

UPPAP, 2002, Second Participatory Poverty Assessment Report: Deepening the Understanding of Poverty. Kampala: Ministry of Finance and Economic Planning. 